\title{
ULTRA LIGHT UAV SYSTEMS FOR THE METRICAL DOCUMENTATION OF CULTURAL HERITAGE: APPLICATIONS FOR ARCHITECTURE AND ARCHAEOLOGY
}

\author{
A. Adami ${ }^{1, *}$, L. Fregonese ${ }^{1}$, M. Gallo ${ }^{1}$, J. Helder ${ }^{1}$, M. Pepe ${ }^{2}$, D. Treccani ${ }^{1}$
}

\author{
${ }^{1}$ Politecnico of Milano, Dept. of Architecture, Built environment and Construction engineering (DABC), Campus Mantova, Italy - \\ (andrea.adami, luigi.fregonese, mara.gallo, jacopo.helder, daniele.treccani)@polimi.it \\ ${ }^{2}$ Politecnico di Bari - Department of Civil, Environmental, Land, Construction and Chemistry - DICATECh -Bari, Italy - \\ massimiliano.pepe@poliba.it
}

\section{Commission II}

KEY WORDS: Photogrammetry, UAV -Unmanned Aerial Vehicle, ultra-light drone, GSD, Cultural Heritage

\begin{abstract}
:
The Italian legislation on Remote Pilot Aircraft Systems (SAPR: Sistema Areomobile a Pilotaggio Remoto), as in 2012, regulates the use of drones in controlled and uncontrolled airspace. In 2016, the regulation introduced simplified procedures for the use of ultralight drones. These instruments are particularly widespread in the field of Cultural Heritage survey. In fact, according to the Italian regulations currently in force it is possible to pilot a drone of less than 300 grams without the need of a flight license and without a specific training course and medical examination and it is not required a special permit to fly in populates areas (although without flying over groups of people). Another possible explanation is the limited cost of these aircrafts and their easy availability on the market, both on the shelves of all electronic shops and in online stores.

Following the boom of drones under $300 \mathrm{~g}$, and considering the new European regulations also pay particular attention to a similar segment of Unmanned Aerial Vehicle (UAV) (in the future for aircraft under $250 \mathrm{~g}$ ), it is important to evaluate the results that can be obtained through these small instruments and above all to evaluate which are the fields of application compatible with the technical limitations imposed by the need to lighten the components onboard (think in particular of the sensors of digital cameras).

The purpose of the study is linked to the documentation of Cultural Heritage, in particular, we want to investigate the quality and metric reliability of photogrammetric surveys carried out through ultra-light drone images. Some application of UAV photogrammetry by ultra-light drones are showed in this paper and they deal with archaeological and architectural survey.
\end{abstract}

\section{INTRODUCTION}

\subsection{Survey from the top}

The documentation of cultural heritage from the top has always played a role of primary importance, because, through it, you can observe details and phenomena otherwise invisible. Where there is the possibility to "stand up" through stairs, buildings, bell towers, the documentation is quite simple and immediate. Otherwise, it is necessary to use systems to "raise" the camera above the usual point of view.

From the very beginning, photography has looked for different ways to take images from the top, but even more so, it has tried to extract metric information from the photographs, through photogrammetry. Aimé Laussedat, referred to as the "Father of Photogrammetry", was probably the first to carry out experiments (abandoned without success) in aerial photogrammetry, in 1858, using a string of kites. It was the French photographer Gaspard Felix Nadar who widely used the photographic technique from a balloon at 80 meters (History of photogrammetry, 2008). Since then, various systems have been used to acquire photographs from the air, from the more traditional ones such as balloons and airships, to the more creative ones such as kites and the pigeons used since 1907.

Since some years ago, photogrammetry, intended as the technique for documenting and surveying cultural heritage, has been widely used also thanks to the release of software that allow you to automate part of the process. In the specific field of aerial photogrammetry, it also takes advantage of the spread of UAV Unmanned Aerial Vehicle) systems, radio-controlled plane with different types of photographic sensors.
As always, after a first phase in which the UAV regulation was inadequate or not well defined, much more detailed regulations were published which partly reduced the scope of drones for safety reasons. In 2012, immediately after the Earthquake in Emilia Romagna, Italy, we surveyed many churches and bell towers in order to evaluate the state of damage (Achille et al, 2015). But according to the following specific regulation, that kind of application would not have been allowed.

In Italy, in fact, ENAC (Ente Nazionale per l'Aviazione Civile the Italian Civil Aviation Authority) published its first regulation in 2013 (Remotely Piloted Aerial Vehicles -RPASRegulation Issue) and it was very difficult to fly over assemblies and historical center. In 2015, with the second edition of the regulation, the possibility of using very light drones was included, even in contexts that were previously prohibited. This has led to the spread of ultra-light drones which, thanks to their ease of use, the possibility of flying even over built-up areas and the absence of the need for any king of license, represent a highly effective tool for documenting cultural heritage.

While the regulations allow their use (clearly under certain conditions), the question arises as to whether the documentation and photogrammetric survey carried out by these drones meets the operators' needs in terms of quality and metric accuracy. The need to reduce the weight of UAV systems (to $300 \mathrm{gr}$ for the Italian regulation, to $250 \mathrm{gr}$ for the European regulation in force since July $\left.1^{\text {st }}, 2019\right)$ also determines some constraints and limitations that it is right to take into account before addressing the survey. 


\subsection{Goal of the paper}

The technical aspects of regulation are not the subject of this research paper (even if they are fundamental for the correct use of UAV systems) as each Country, European Community included, has the possibility to accept the legislation and to amend it according to its own needs. (even if they are fundamental for the correct use of UAV systems).

This article does not even address the mechanical and electronic design, nor the operation, of ultralight drones as it is believed that this topic is not closely related to the activities of survey and documentation, but rather related to the development of new systems in the field of electronic engineering.

It should be noted, for clarity, that the ultralight drones mentioned in the article, fall within the group of multi-rotors, and thus exclude all fixed-wing systems or other.

In this article, instead, we want to focus on the limitations imposed by the low weight of these FVOs and, through application cases divided according to the objective of the survey, analyze how these constraints have been circumvented or resolved. The work aims at highlighting both the metrical aspects of the procedures and of the works obtained, and at clarifying the different fields of application and the advantages linked to the top-down view.

After a brief report on other similar experiences (par 1.3), we will describe the characteristics of light drones (par 2.1), focusing on the aspects most related to the photogrammetric survey and their limits (par 2.2) and in particular, the use of targets for the georeferencing of data is addressed (par 2.3). In chapter 3 we will describe different application cases of UAVphotogrammetric survey for the documentation of archaeological sites (par 3.1), architectural elevations (par 3.2) and for the mapping of architectures from above (par 3.3). Through the analysis and validation of the results obtained in these different cases, we want to suggest some approaches to ensure a result suitable for the scale and purpose of the survey.

\subsection{Related works}

UAV survey is a very discussed subject in the scientific literature, and this is essentially linked to the fact that UAV systems have now reached affordable prices and allow to obtain acceptable results for most applications in architecture and archaeology.

An overview of remote-controlled systems and possible applications in the AEC (Architecture, Engineering and Construction) sector is provided in (Shakhatreh et al, 2018) and (Gilles et al, 2019). (Nex and Remondino, 2014) instead, provided a more detailed review in the Cultural Heritage domain and possible applications, especially with regard to mapping and 3d survey.

Many scientific publications aim to define standards and guidelines for drone-based surveying (Federman et al, 2017) or for specific operations such as facade surveys (Palanirajan et al, 2019). In many other cases, however, there is work done with the relative validation of data, confirming the effectiveness of drones in cultural heritage surveys.

As concerning ultra-light drones, there is a large number of websites and online publications describing the photogrammetric survey pipeline. However, it is necessary to specify that, in this article, we are dealing with multi-copter drones, so that, many of the resources in the literature, about fixed-wing drones, cannot be mentioned.

(Calantropio et al, 2018) present an interesting comparison between low cost systems for the survey of the built heritage and among these is mentioned the use of ultralight drones (Dji Spark in particular).

\section{VERY LIGHT UAV SYSTEMS}

\subsection{Characteristics}

Ultra-light drones, in this article, are remote-controlled systems with a payload of less than 300 gr. The European regulation, in force since July 2019 and expected to be adopted at national level by 2020, sets the limit for this category at 250 grams. Currently, major consumer drone manufacturers, such as DJI, are bringing to market new models that are below this limit (presentation of the new Dji Mavic Mini drone scheduled for October $30^{\text {th }}$, 2019). However, being a very recent fact, we refer you to a further study, dedicated to systems under 250 gr.

The panorama of drones under $300 \mathrm{~g}$ is very wide and it is necessary, first of all, to discriminate between toy systems and those that can be used for semi-professional applications. Among the latter, although there are many models that can also be self-assembled or modified, the most used UAV systems are those produced by the two main manufacturers: DJI (china) and Parrot (France).

The characteristics of the two drones related to the photographic aspects, DJI Spark and Parrot Anafi, both around $300 \mathrm{~g}$ (with the need for minor modifications to bring them into the regulation) are described in Table 1 . These characteristics are often determined by the weight constraint (payload) and the most significant effects, at least as far as the use of these systems for photogrammetric purposes is concerned, are related to the on-board sensors and the batteries. For a complete description of the two UAV systems, see the manufacturers' websites (https://www.dji.com; https://www.parrot.com/)

\begin{tabular}{|l|l|l|}
\hline & Dji Spark & Parrot Anafi \\
\hline Payload (gr) & $300 \mathrm{gr}$ & $320 \mathrm{gr}$ \\
\hline Dimension (mm) & $143 \times 143 \times 55$ & $244 \times 67 \times 65 \mathrm{~mm}$ \\
\hline Battery life (min) & $16 \mathrm{~min}$ & $25 \mathrm{~min}$ \\
\hline Sensor type & CMOS & CMOS \\
\hline Sensor size (Mpixel) & 12 & 21 \\
\hline Sensor dimensions (inch) & $1 / 2.3 ”$ & $1 / 2.4 ”$ \\
\hline Sensor dimensions (mm) & $6.17 \times 4.56$ & $5.90 \times 4.43$ \\
\hline Image size (pixel) & $3968 \times 2976$ & $5344 \times 4016$ \\
\hline Pixel size (mm) & 0.00155 & 0.0011 \\
\hline Focal length (mm) & 4.49 & $3.92-11.76$ \\
& $25 \mathrm{~mm}$ equiv & $23-69$ equiv \\
\hline Aperture (f-stop) & F/2.8 & F/2.4 \\
\hline
\end{tabular}

Table 1. Photographic characteristics of the most widespread UAV systems

The two systems have very different characteristics from a photographic point of view. The DJI Spark, in fact, uses a system with a pixel size of $0.00155 \mathrm{~mm}$ and a sensor of 12 Mpixel, while the pixel size of the Parrot Anafi is $0.0011 \mathrm{~mm}$ and the sensor of 21 Mpixel. The two systems are almost equivalent: one is superior for the size of the sensor, the other for the pixel size and therefore in quality.

The optics used are also very different. The DJi system has a fixed lens of $25 \mathrm{~mm}$ equivalent, the Parrot, instead, uses a zoom system (23-69 equiv). In addition, while the gimbal of the Spark allows a rotation from $-85^{\circ}$ (almost nadir) to $0^{\circ}$ (horizontal), the Anafi allows a rotation of $180^{\circ}$, i.e. a rotation from $-90^{\circ}$ (nadir) to $+90^{\circ}$ (zenith)

These considerations, in particular related to focal length and gimbal, show that drones have a quite different address. The Dji 
drone seems to be more usable in the photogrammetric field thanks to the fixed lens, the size of the pixel size, while the Parrot drone is more suitable for inspection operations and not strictly metric.

\subsection{Limitations and lacks}

From the characteristics described above, it can be seen that the weakest point of the ultra-light UAV systems applied to photogrammetric surveying in architecture and culture is connected to the coverage of each single pixel on the ground GSD (Ground Sample Distance). Often, in fact, the need to document the details of the assets, collides with the large number of photos to be acquired and this leads to problems in the further phase of orientation and calculation.

To this end, the table used in the photogrammetric flight project is proposed, which relates the final scale of the survey, the GSD corresponding to the final scale of the survey (final GSD), the GSD of the photographic acquisitions (initial GSD) and the corresponding flight height by using the same equation (1) described after in the paper. Specifically, the value of the initial GSD is calculated, on the basis of the sampling theorem of Nyquist-Shannon on digital signals: it defines that the sampling frequency should be twice the frequency of the acquired signal. The theorem, reported to the GSD concept, determines that, if a final GSD of $1 \mathrm{~cm}$ is desired, the initial GSD must be at most $0.5 \mathrm{~cm}$. The values in table 2 are calculated using the characteristic data of the Dji Spark.

\begin{tabular}{|l|l|l|l|}
\hline Scale & $\begin{array}{l}\text { Final GSD } \\
(\mathrm{m})\end{array}$ & $\begin{array}{l}\text { Initial GSD } \\
(\mathrm{m})\end{array}$ & $\begin{array}{l}\text { Height } \\
(\mathrm{m})\end{array}$ \\
\hline $1: 50$ & 0.01 & 0.005 & 14,5 \\
\hline $1: 100$ & 0.02 & 0.01 & 29 \\
\hline $1: 200$ & 0.04 & 0.02 & 58 \\
\hline $1: 500$ & 0.1 & 0.05 & 145 \\
\hline
\end{tabular}

Table 2. Relationships between survey representation, GSD and flight height

To fully evaluate the difference between ultra-light and other UAV systems, we propose the comparison between the survey project carried out with DJI Spark and DJI Mavic 2 pro, also lightweight, but not in the ultralight category. The flight height, the number of photographs, the number of swipes and the flight time required to carry out the planimetric survey of a part of Palazzo Ducale in Mantua (with a GSD of $0.01 \mathrm{~m}$ ) are calculated in table 3 and the two flight plans are in figure 1.

\begin{tabular}{|l|l|l|}
\hline & \multicolumn{1}{|c|}{ Dji Spark } & \multicolumn{1}{|c|}{$\begin{array}{c}\text { Dji Mavic 2 } \\
\text { Pro }\end{array}$} \\
\hline Flight Height & 29 & 44 \\
\hline Num of images & 232 & 139 \\
\hline Num of strips & 17 & 13 \\
\hline
\end{tabular}

Table 3. Comparison between survey flight project of an ultralight UAV (Dji spark) and other systems (Dji Mavic 2 pro)

The example clearly highlights one of the difficulties associated with ultralight systems. In fact, it is necessary to use many more photos than those that would have been used with other systems and this means more processing time and the possibility of making much more mistakes in photogrammetric processing. The low resolution of the sensors, and what follows, not only determines a high number of photos, but can also cause errors in the phase of orientation and georeferencing of data due to the poor recognition of features in the images.
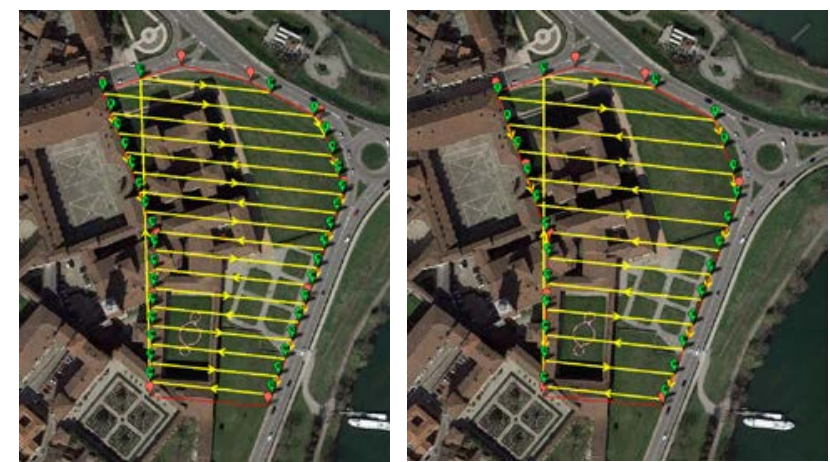

Figure 1. Flight plan of a part of Palazzo Ducale in Mantova by two UAVs (on the left the ultralight Dji Spark), on the right the very light Dji Mavic. Flight plan was carried out by Mission planner software

\subsection{Target recognition}

In this part of the research, we want to investigate the relationship between GSD (Ground Sample Distance) of the image and dimension of the markers using SfM (Structure from Motion) approach. Indeed, an easy recognition of markers would speed up digital processes in order to build threedimensional models or orthophotos. To achieve this aim, two types of markers were used: circular 12 bit and cross-coded. In addition, for this last type of marker the influence of the color was investigated. The GSD of the image generated by frame camera is related to the focal length (c), the flight height (z) and the pixel size (CCD pixel size), by the following relation (Linder W. 2003) (Pepe et al., 2018):

$$
\mathrm{GSD}=\mathrm{Z} / \mathrm{c} \text { CCD pixel size }
$$

Therefore, starting from the formula (1) and fixing the GSD, it is possible to obtain the flight height (or the distance) from the target and sensor. In this case study, we tested two types of target: circular 12 bit and (square) cross. In particular, for the circular 12-bit target, we considered the following dimensions: $1 \mathrm{~mm}, 2 \mathrm{~mm}, 3 \mathrm{~mm}, 4 \mathrm{~mm}, 5 \mathrm{~mm}$ and $10 \mathrm{~mm}$. The values of reference are the radius measure evaluated from the centre to external boundary of target. As concerns the cross-coded target, we considered the following dimensions: $10 \mathrm{~mm}, 20 \mathrm{~mm}, 30 \mathrm{~mm}$, $40 \mathrm{~mm}$ and $50 \mathrm{~mm}$. In this last case, measures of the cross-coded target are referred to length of the side. In addition, for crosscoded target, the influence of the colour in the automatic recognition of the target was tested. The diverse colours of the targets used for this experimentation are reported in the Figure 2.

The automatic recognition of the targets was carried out in Agisoft Photoscan software V.1.4.4. In order to recognize the target in automatic way, this software requires stereoscopy images and alienated images. Therefore, for each flight height tested, a dataset containing more images were realized (table 4). The automatic recognition of the targets was carried out in Agisoft Photoscan software V.1.4.4. In order to recognize the target in automatic way, this software requires stereoscopy images and alienated images. Therefore, for each flight height tested, a dataset containing more images were realized (table 4). 


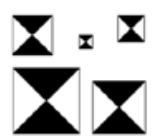

(a)

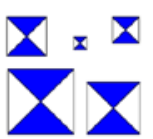

(b)

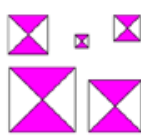

(c)

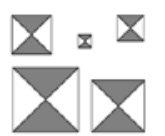

(d)

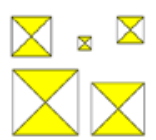

(e)

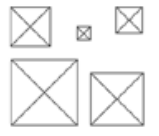

(f)

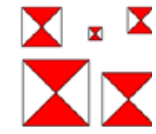

(g)

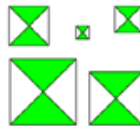

(h)

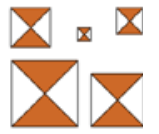

(i)

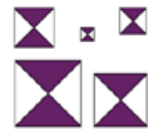

(l)
Figure 2. Several colours of cross-coded tested

\begin{tabular}{|c|c|c|}
\hline $\begin{array}{c}\text { Dataset } \\
(\#)\end{array}$ & $\begin{array}{c}\text { GSD } \\
(\mathbf{m m})\end{array}$ & $\begin{array}{c}\text { Distance target - object } \\
(\mathbf{m})\end{array}$ \\
\hline 1 & 0.1 & 0.287 \\
\hline 2 & 0.5 & 1.433 \\
\hline 3 & 1 & 2.866 \\
\hline 4 & 2 & 5.732 \\
\hline 5 & 3 & 8.598 \\
\hline
\end{tabular}

Table 4. Relation GSD Vs Flight height

The first targets taking into consideration were the circular 12 bit in the diverse dimensions and the cross-coded in black/white (Figure 2.a) of diverse dimension of the side. The results of the several tests, characterized by the software's ability to recognize targets, are summarize in the tables 5 and 6.

\begin{tabular}{|c|c|c|c|c|c|c|}
\hline \multirow{2}{*}{$\begin{array}{c}\text { Dataset } \\
(\#)\end{array}$} & \multicolumn{6}{|c|}{ Automatic recognition of circular 12 bit } \\
\cline { 2 - 7 } & $\mathbf{1 m m}$ & $\mathbf{2 m m}$ & $\mathbf{3 m m}$ & $\mathbf{4 m m}$ & $\mathbf{5 m m}$ & $\mathbf{1 0 m m}$ \\
\hline 1 & Yes & Yes & Yes & Yes & Yes & No \\
\hline 2 & No & Yes & Yes & Yes & Yes & Yes \\
\hline 3 & No & No & No & Yes & Yes & Yes \\
\hline 4 & No & No & No & No & No & Yes \\
\hline 5 & No & No & No & No & No & No \\
\hline
\end{tabular}

Table 5. Automatic code recognition using circular 12-bit target

\begin{tabular}{|c|c|c|c|c|c|}
\hline \multirow{2}{*}{$\begin{array}{c}\text { Dataset } \\
(\#)\end{array}$} & \multicolumn{5}{|c|}{ Automatic recognition of cross-coded } \\
\cline { 2 - 6 } & $\mathbf{1 0 m m}$ & $\mathbf{2 0 m m}$ & $\mathbf{3 0 m m}$ & $\mathbf{4 0 m m}$ & $\mathbf{5 0 m m}$ \\
\hline 1 & Yes & Yes & Yes & Yes & Yes \\
\hline 2 & Yes & Yes & Yes & Yes & Yes \\
\hline 3 & No & Yes & Yes & Yes & Yes \\
\hline 4 & No & No & No & Yes & Yes \\
\hline 5 & No & No & No & No & No \\
\hline
\end{tabular}

Table 6. Automatic code recognition using cross-coded target

As regards the influence of the color of the cross-targets, we obtained the same results regardless of color, except for the yellow targets (Figure 2.e) and the targets without background (Figure 2.f) for each distance exanimated.

Therefore, summarizing the result obtained in the several test, it is possible to build the graphs for circular 12 bit and crosscoded targets (Figure 3).

\section{CASE STUDIES}

\subsection{Archaeological survey}

During the excavations of the Naples underground, numerous archaeological finds were found, attributable to different periods of the city of Naples (Italy).
Most of the findings were discovered in the excavations of the "Toledo", "Municipio", "Università" and "Duomo" stations, located in the southern part of the city (along the line 1 of the metro station). In this paper, it is reported a case study concern the "Duomo" station.
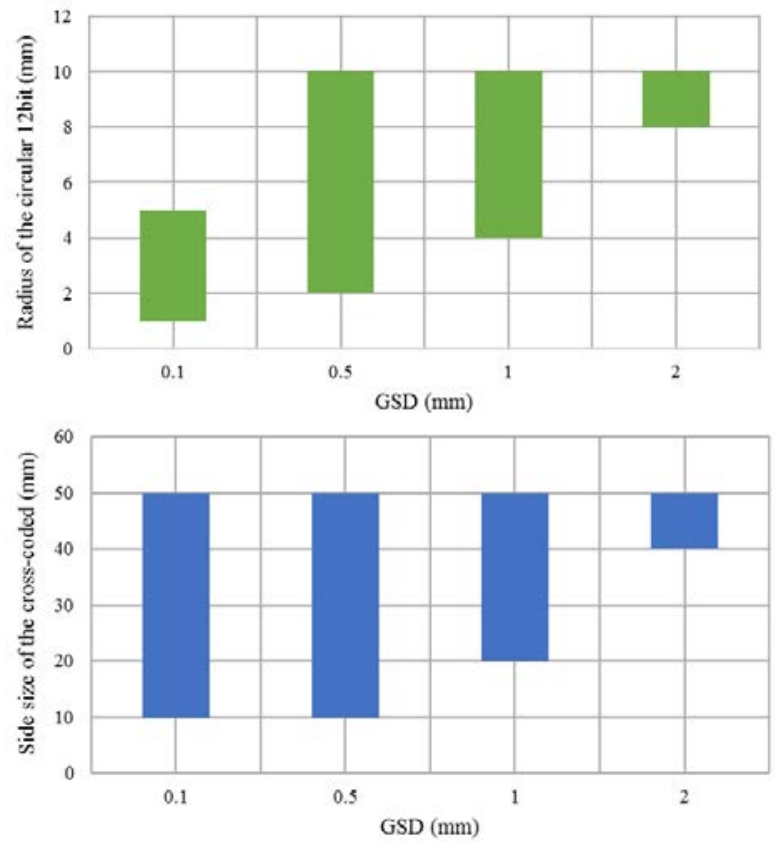

Figure 3. Correlation between GSD and target dimension using Circular 12bit (a) and Cross-coded tested (b)

The survey of an antique artifact (presumably medieval) was realized by the camera supplied with the DJI Spark drone.

The dataset is constituted by 67 aerial images generated by the camera of DJI Spark drone. In this case study, 11 cross-coded markers (or even called "targets") of the square dimension of $30 \mathrm{~mm}$ x $30 \mathrm{~mm}$ were used.

The coordinates of each target within a local coordinates system were determined by measuring them with a Leica TCRA1103+ total station. The topographic elaboration of the marker was carried out in Leica Geoffice v. 8.0 environment whose main parameters are reported in the table.

The elaboration of the images was performed using Agisoft Metashape software. As known, the process of the image was obtained performing more steps: alignment, build dense cloud, build mesh and build orthomosaic.

So, the first step was the alignment of the images. Once verified that all the images were aligned and located in right position, the positions of the markers on the images were researched. The markers were recognition in automatic way using a special tool developed in the software. In this way, associating the coordinates of the markers (calculated topographically) to the images, it was possible to verify the geometric quality of the alignment. The standard deviation achieved in this project was 3 $\mathrm{mm}$, as shown in the following table 7.

The next steps were the building of the dense cloud, the mesh and the orthomosaic with a pixel resolution of $2 \mathrm{~mm}$. Therefore, at the end of these processes, it was possible to obtain the 3D point cloud (figure $4 \mathrm{a}$ ) and the orthophoto (figure $4 \mathrm{~b}$ ) 


\begin{tabular}{|l|r|r|r|r|}
\hline marker & \multicolumn{1}{|c|}{$\begin{array}{c}\text { East } \\
(\mathbf{m})\end{array}$} & $\begin{array}{c}\text { Nord } \\
(\mathbf{m})\end{array}$ & $\begin{array}{c}\text { Elevation } \\
(\mathbf{m})\end{array}$ & \multicolumn{1}{c|}{$\begin{array}{c}\text { Error } \\
(\mathbf{m})\end{array}$} \\
\hline M01 & 7786.156 & 2113.516 & 2.412 & 0.008 \\
\hline M02 & 7786.647 & 2111.078 & 2.484 & 0.008 \\
\hline M03 & 7785.09 & 2112.575 & 2.361 & 0.003 \\
\hline M04 & 7783.867 & 2113.73 & 2.387 & 0.006 \\
\hline M05 & 7783.896 & 2112.011 & 2.342 & 0.005 \\
\hline M06 & 7783.911 & 2110.476 & 2.284 & 0.009 \\
\hline M07 & 7783.926 & 2114.764 & 3.015 & 0.001 \\
\hline M08 & 7786.98 & 2114.397 & 3.714 & 0.008 \\
\hline M09 & 7787.248 & 2110.945 & 3.646 & 0.008 \\
\hline M10 & 7783.488 & 2109.531 & 3.587 & 0.008 \\
\hline M11 & 7782.181 & 2113.457 & 3.643 & 0.010 \\
\hline
\end{tabular}

Table 7. Evaluation of the error on the markers
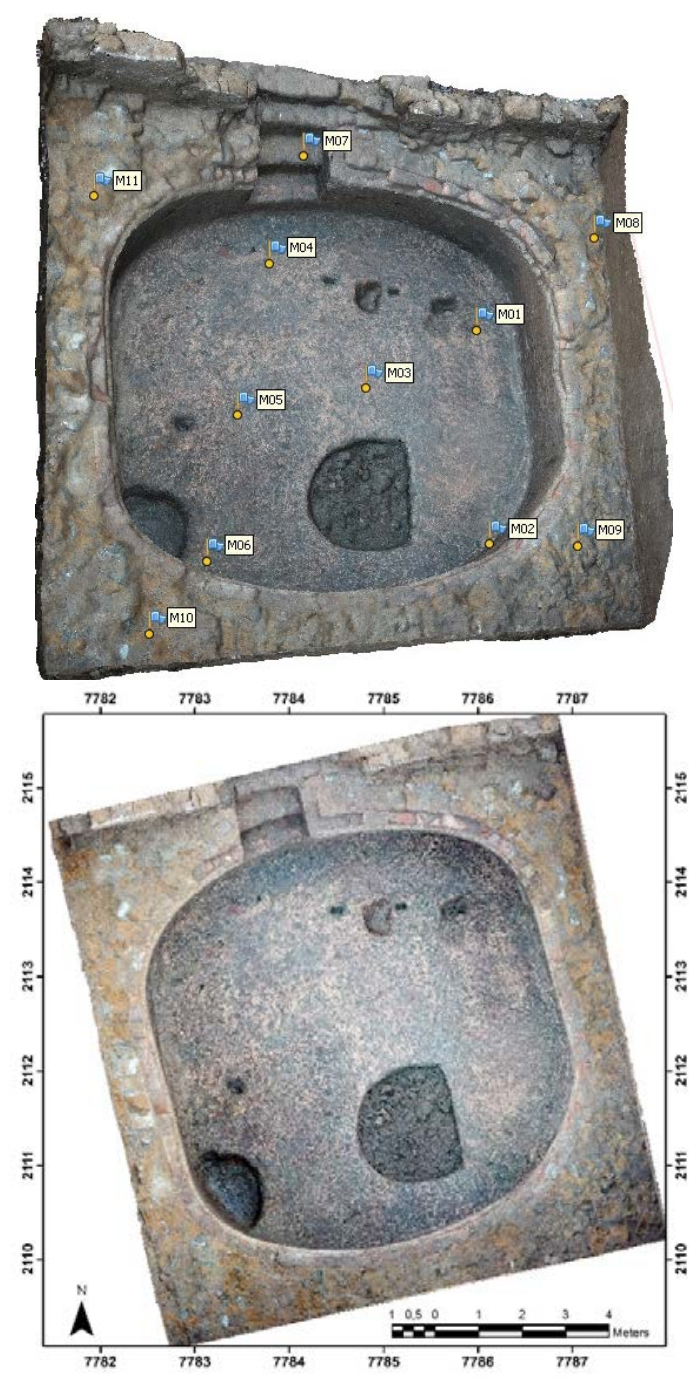

Figure 4. 2D and 3D models obtained by aerial survey and postprocessing in SfM environment. a) 3D point cloud with indication of the markers b) Orthophoto of the archaeological artefact located in the excavation of "Duomo" metro station, in the city-center of Naples, Italy

\subsection{Architectural elevation}

For cultural heritage documentation, orthophotos of building facades represent a very important feature as they represent a fundamental tool for the preservation of the architecture itself. Architectural orthophotos traditionally are obtained by using terrestrial images, but there is often the lack of those details which are not visible from the ground. For example, taking photos only from ground can lead to loss of details hidden from the sight by moulding and decorations.

In addition, when the facades are quite high, the quality of the upper parts of the orthophotos is often lower because of the perspective effect present in the photos acquired from the ground. The pixels of the highest parts, and therefore distant, cover a greater portion of the surface. This can result in a decrease in quality if the photos cannot be captured from high positions (and it is not always possible to use the lifting platforms).

According to all this, the case study of Villa Forni Cerato is interesting to evaluate the reliability of ultra-light UAV systems for the documentation of architectural elevations. The villa, located in Montecchio Precalcino, in the province of Vicenza, Italy was probably designed by the Italian architect Andrea Palladio, in 1565. The building is part of the world heritage sites of UNESCO since 1996. In latest years the building was abandoned but in August 2018 restoration works started. So there was the necessity of a complete and accurate representation of the whole villa.

The use of an ultra-light drone made possible to take photos of the whole façade with an initial GSD of $0.0024 \mathrm{~m}$. The drone used was DJI spark and we took 883 photos. The flight was developed so that the drone moved orthogonally to the façade, trying to maintain the same distance, even along the sides of the porch. In the dataset there are also some strips rotated (not orthogonal) respect to main plane of the façade, to guarantee a better and more stable alignment. Photos were processed by means of Agisoft Metashape. For the specific case the resulting orthophoto has a GSD of $0.004 \mathrm{~m}$ (Figure 5).

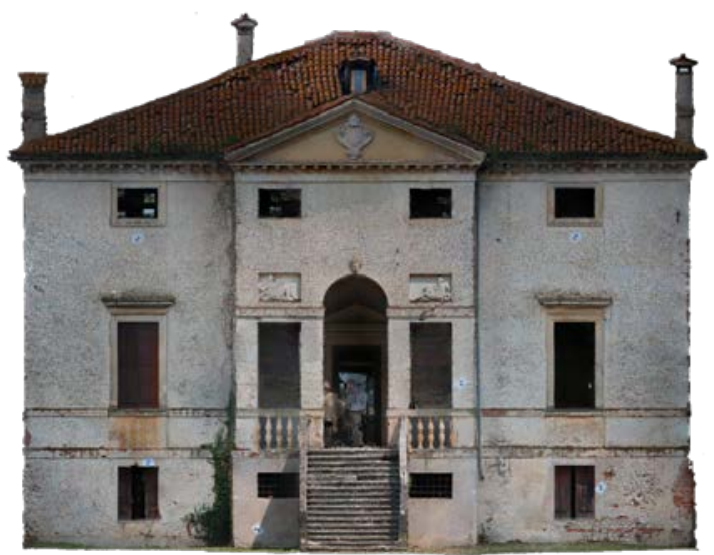

Figure 5. The study case: the main façade of Villa Forni Cerato, in Montecchio Precalcino, Vicenza. The orthophoto has a GSD of $0.004 \mathrm{~m}$. The orthophoto elaborated from UAV images includes also the roof, which usually is not acquired.

Architectural points on the façade were surveyed by a total station to georeference the point cloud on the basis of a topographic network. We also developed a laser scanner survey, using a Leica HDS 7000. The accuracy of the photogrammetric point cloud is assessed by comparing it with a single laser scanner point cloud, georeferenced in the same system. The software used was CloudCompare, which compute the absolute 
distances of points pertaining to two point-clouds. Figure 6 shows the photogrammetric point cloud remapped by Cloud Compare with a false colour gradient depending on absolute distance of points. The maximum calculation distance is set to $0.05 \mathrm{~m}$ in order to emphasise the holes related to hidden portions of façade. In fact, red portions are the zones where laser scanner point clouds have holes, as in the spaces between the notches of the mouldings, the inner part of last floor and, of course, the roof.

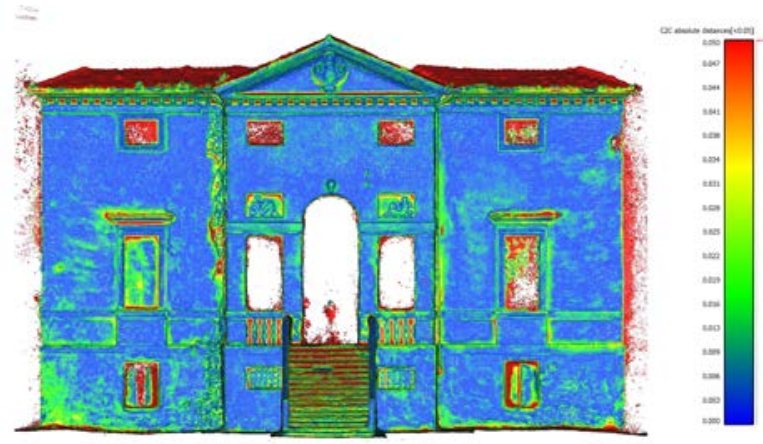

Figure 6. Comparison between point cloud from laser scanner and from photogrammetry. In red the area with an errordifference of $5 \mathrm{~cm}$. In most cases, the areas in red are parts not surveyed by laser scanner because hidden from the sight due to scan position. They were surveyed, instead, by drone

As a result, the use of ultra-light drones23 for this work made possible to get more details with the same accuracy of laser scanner ground scan as compared to the ground position. This approach has also the advantage of documenting even the hidden part of the architecture as moulding and roofs.

\subsection{Architectural mapping}

The roofs are a very interesting subject for photogrammetric UAV survey as they are difficult to document with any other systems and they require a high accuracy to recognise each single tile. The orthophoto, specific outcomes of this survey, is of great interest for restorers as it allows to investigate not only the geometry of the roof but also the state of decay.

The case study is the church dedicated to the Annunciation of the Blessed Virgin Mary (Chiesa dell' Annunciazione della Beata Vergine Maria) located in Roverbella, a small town in the province of Mantova, Italy.

Built in 1766 in place of a previous temple, the church, with a longitudinal plan and a single nave, is of late Baroque style and presents everything in a decorative rococo-style stucco. The church itself measure about $30 \mathrm{~m}$ in the largest part and is long $40 \mathrm{~m}$; the facade is $28 \mathrm{~m}$ tall, while the bell tower reaches about $38 \mathrm{~m}$ in elevation.

The building surroundings are quite a suitable working condition thanks to the parking area and the consequent presence of a wide space in front of it; only a corner of the church is attached for a small portion to another building and the sides of it are characterized by relatively narrow passages but these conditions do not represent a problem using a small UAV.

The main purpose of this survey was to return the entire church by integrating the internal laser scanner data with the external drone data, highlighting particular attention to the study of the ceiling and the roofing. One of the necessities of this case was the generation of an orthophoto to define the geometry and state of preservation of the roofing.
Even though the building's surroundings are not much congested, the church is still located in an historical centre and to avoid flying in critical conditions, according to the legislation, we opted for the ultralight UAV a DJI Spark.

Weather conditions were acceptable except for a strong wind, still within legal safe limits, but that, due to the light weight of the UAV, would still create problems in maintaining positions and a straight flight path.

It was therefore decided to do a manual flight and to automatic take a picture every 2 seconds at a reduced cruising speed, below $1 \mathrm{~m} / \mathrm{s}$, in order to have an abundant overlapping of pictures and be able to select after which ones to hold for the processing of the orthophoto.

Images were acquired first nadiral to the roof and then with sloped axis from each side of the building, from the facade to the apse and back for a total of 11 strips.

From a total of 832 pictures, 452 of them were used to obtain a reliable data of the roof.

Although at the terrain level we have obtained an average Ground Sample Distance (GSD) of $1 \mathrm{~cm}$ it was possible to achieve an orthophoto with a resolution of $5 \mathrm{~mm} /$ pixel of the roof.

A total of 9 cross-non coded target, dimension $30 \times 30 \mathrm{~cm}$, were positioned around the church to serve as GCP and were measured during the topographic survey by Leica TS30 to georeferenced the photogrammetric model

The mean error in camera alignment was 0.7 pixels after optimization, while the root mean square error (RMSE) of the ground control points obtained at the end of the georeferencing is of $7 \mathrm{~mm}$.

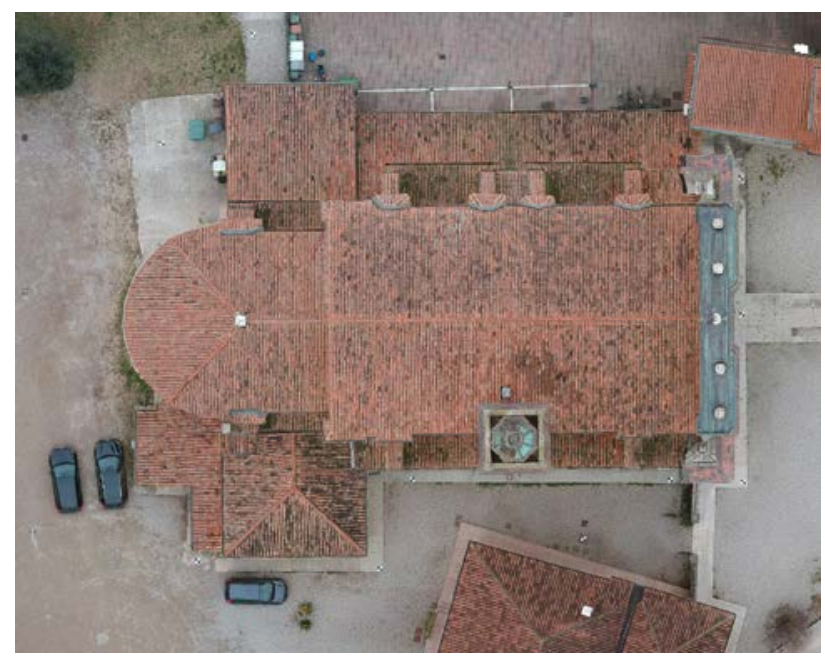

Figure 7. Orthophoto of the roof the Church in Roverbella at the scale 1:50, with a GSD (on the roof) of $5 \mathrm{~mm}$

The choice to use an UAV in this case was almost a necessity.

Although the church has a lot of free space on the facade and in the back, the narrow side passages would have prevented the access of an aerial working platform, without even considering the high costs due to the rental fees and employment of certified personnel to handle this equipment and to work at height.

Not to mention the issues related to the accessibility of some points of the roof.

Finally, the use of a small UAV has allowed a drastic reduction of acquisition time, taking less than an hour to survey the entire roof, the bell tower and the main facade with the employment of only one person. 


\section{CONCLUSIONS}

The applications described above show that photogrammetric survey can also be done with ultra-light drones. However, it is necessary to pay attention to some aspects, mainly related to the photographic characteristics of the drones themselves. Among these, the most relevant aspects to consider are the evaluation of the GSD and of the distance of acquisition: they are both connected to the small size of sensor. For the same reason, it is important to choose carefully the targets to be used, not only with the aim of automating the process, but also to minimize the possibility of error.

Compared to photogrammetric models, it should be noted that those made up by not high-resolution photos (12 Mpixel in the case of Dji Spark) must handle a number, sometimes considerable, of photographs. However, no other limits have been found, if we follow the same workflow of terrestrial photogrammetry.

The elaborations have also demonstrated the validity of the ultra-light drones as tools for the documentation of cultural heritage. The possibility of flying, as provided by the regulations, in inhabited centers, makes it possible to create orthophotos of the facades and roofs, complete in all their parts and in high definition, in order to achieve, in this way, a truly complete documentation.

The new versions of the regulations, in particular the lowering of the threshold payload, will certainly affect the production of new systems, which are becoming lighter and lighter. However, the market for ultra-light drones will have to be monitored to ensure that the lightening of the weight does not affect the characteristics too much.

\section{REFERENCES}

Achille C., Adami A., Chiarini S., Cremonesi S., Fassi F., Fregonese L., Taffurelli L., 2015. UAV-Based Photogrammetry and Integrated Technologies for Architectural ApplicationsMethodological Strategies for the After-Quake Survey of Vertical Structures in Mantua (Italy). Sensors 2015, 15, pp.15520-15539.

Calantropio, A., Chiabrando, F., Rinaudo, F., and Teppati Losè, L., 2018: Use and evaluation of a short-range small quadcopter and a portable imaging laser for built heritage 3D documentation, Int. Arch. Photogramm. Remote Sens. Spatial Inf. Sci., XLII-1, 71-78, https://doi.org/10.5194/isprs-archivesXLII-1-71-2018, 2018.

Chiabrando F., Nex F., Piatti D., Rinaudo F., 2011, UAV and RPV systems for photogrammetric surveys in archaelogical areas: two tests in the Piedmont region (Italy)

J. Archaeol. Sci., 38 (3) (2011), pp. 697-710

Federman, A., Santana Quintero, M., Kretz, S., Gregg, J., Lengies, M., Ouimet, C., and Laliberte, J., 2017: UAV photogrammetric workflows: a best practice guideline, Int. Arch. Photogramm. Remote Sens. Spatial Inf. Sci., XLII-2/W5, 237-244, https://doi.org/10.5194/isprs-archives-XLII-2-W5237-2017, 2017.

Gilles A., Masoud G., Bryan W. F., 2019. A systematic review of unmanned aerial vehicle application areas and technologies in the AEC domain. Journal of Information Technology in Construction (ITcon), Vol. 24, pg. 381-405
History of Photogrammetry, 2008, at https://ibis.geog.ubc.ca/courses/geob373/lectures/Handouts/Hist ory_of_Photogrammetry.pdf (last visit October 2019)

Linder W., 2003. Digital Photogrammetry. A Practical Course. Springer

Nex F., Remondino F., 2014. UAV for 3D Mapping Applications: A Review. Applied Geomatics 6 (1): 1-15.

Palanirajan, H. K., Alsadik, B., Nex, F., Oude Elberink, S. 2019. Efficient flight planning for building façade 3d reconstruction, Int. Arch. Photogramm. Remote Sens. Spatial Inf. Sci., XLII-2/W13, 495-502, https://doi.org/10.5194/isprsarchives-XLII-2-W13-495-2019, 2019.

Pepe M., Fregonese L., Scaioni M., 2018. Planning airborne photogrammetry and remote-sensing missions with modern platforms and sensors. European Journal of Remote Sensing, 51(1), 412-436.

Shakhatreh H., Sawalmeh A., Al-Fuqaha A., Dou Z Almaita, E., Khalil I., Othman N., Khreishah A., Guizani M., 2018. Unmanned Aerial Vehicles (UAVs): A Survey on Civil Applications and Key Research Challenges. IEEE Access. 7. 10.1109/ACCESS.2019.2909530. 